\title{
Pancreatic cancer: Who benefits from curative resection?
}

\author{
HG Beger MD, F Gansauge MD, G Leder MD
}

HG Beger, F Gansauge, G Leder. Pancreatic cancer: Who benefits from curative resection? Can J Gastroenterol 2002;16(2):117-120.

Surgical resection is the only chance for cure of pancreatic cancer. Unfortunately, the majority of patients have grossly unresectable disease. Patients with stage I or II disease according to the criteria of the International Union Against Cancer (UICC) should be considered for potentially curative surgery. The goal of surgery is to remove the entire tumour with no residual disease (oncological RO resection), which requires extensive resection of the surrounding tissues. Even if lymph nodes are histologically free of disease, molecular biological techniques reveal infiltration with cancer cells in $50 \%$ of cases. Therefore, extensive local resection combined with radical resection of lymphatic tissue, including lymph nodes around the head of the pancreas, retroperitoneal tissue and neural plexus around the great vessels, affords a longer median survival time than standard resection alone. Even patients with UICC stage III disease can undergo aggressive surgical treatment, but their chances for long term survival are low. Some patients develop severe diarrhea after circumferential removal of nerve tissue around the superior mesenteric artery. Adjuvant radiochemotherapy also provides a modest prolongation of survival. Despite these advances, the prognosis for pancreatic cancer is still poor, and spread of tumour within the peritoneum and to the liver is common postoperatively.

Key Words: Pancreatic cancer; Surgical resection

\section{Cancer du pancréas : qui profite de la résection curative?}

RÉSUMÉ : La résection chirurgicale constitue le seul moyen de guérir le cancer du pancréas. Malheureusement, la majorité des patients sont atteints d'une maladie non résécable. La chirurgie potentiellement curative devrait être envisagée chez les patients atteints d'un cancer de stade I ou II selon les critères de l'Union internationale contre le cancer (UICC). L'intervention consiste en l'exérèse complète de la tumeur, sans maladie résiduelle (résection R0), qui nécessite la résection étendue des tissus environnants. Même si les ganglions lymphatiques ne sont pas atteints sur le plan histologique, dans $50 \%$ des cas, les techniques de biologie moléculaire révèlent leur infiltration par des cellules cancéreuses. Par conséquent, la résection locale étendue, associée à la résection radicale des tissus lymphatiques, y compris des ganglions lymphatiques autour de la tête du pancréas, du tissu rétropéritonéal et du plexus nerveux autour des gros vaisseaux, offre un temps de survie médian supérieur à celui de la résection usuelle. Même les patients atteints d'un cancer de stade III selon l'UICC peuvent subir un traitement chirurgical énergique, mais leurs chances de survie à long terme demeurent minces. Une diarrhée grave apparaît chez certains patients après l'exérèse circonférentielle du tissu nerveux autour de l'artère mésentérique supérieure. La radiochimiothérapie adjuvante permet de prolonger quelque peu la survie. Malgré ces progrès, le pronostic du cancer du pancréas demeure médiocre, et l'extension de la tumeur dans le péritoine et le foie n'est pas rare après l'opération.

Department of General Surgery, University of Ulm, Ulm, Germany

Correspondence: Dr HG Beger, Department of General Surgery, University Hospital, Steinhövelstrasse, 9 D 89075, Ulm Donau, Germany.

Telephone+49-731-500-26775, fax+49-731-500-26786, e-mail hans.beger@medizin.uni-ulm.de

Received for publication December 3, 2001. Accepted December 3, 2001 
Pancreatic cancer is a highly malignant disease, and the mortality rates are nearly as high as the incidence rates. The annual incidence is 10,500 in Germany and 27,000 in the United States. The two-year survival rate is only $5 \%$ to $10 \%$. The incidence increases after age 30 years, and the peak mortality occurs between ages 65 and 72 years in Europe, and between ages 55 and 75 years in the United States.

Sites of disease dissemination include lymphatic channels and regional lymph nodes, retropancreatic tissues, bile duct, duodenum, liver, peritoneum, local vascular invasion and extrapancreatic nerve plexus (1-4). Isolated dormant tumour cells can be found in the bone marrow and liver at the time of diagnosis in $20 \%$ to $60 \%$ of patients. Invasion of the common bile duct, duodenum, liver, and local and distant parts of the peritoneum occur early in this disease. Free tumour cells are detected in the peritoneum at the time of surgery in one-third of patients (5).

Approximately $80 \%$ of patients with ductal pancreatic cancer have histological evidence of lymph node involvement (6). In cases in which the primary tumour was less than $2 \mathrm{~cm}$ in diameter, Tsuchiya et al (7) were able to demonstrate metastases in lymph nodes (in 30\%), extrapancreatic retroperitoneal tissues (in 20\%), serosal walls (in $10 \%$ ) and vascular walls (in 6\%).

Neural and perineural invasion can be demonstrated in $40 \%$ to $60 \%$ of surgical resection specimens (7). Sites of involvement are the intrapancreatic and extrapancreatic nerves, including perivascular nerves, plexus around the portal and superior mesenteric veins, and the sympathetic ganglia to the right of the aorta. Extrapancreatic nerve involvement is correlated with a poor prognosis.

\section{TUMOUR-RELATED PROGNOSTIC FACTORS}

On the basis of knowledge about tumour growth in pancreatic cancer, several factors that favourably influence the prognosis have been identified. These factors include a tumour size of less than $2 \mathrm{~cm}$ in diameter, absence of lymph node metastases, lack of involvement of vessel walls and lack of nerve involvement (Table 1).

The most important predictor of long term survival is the ability to resect the tumour completely; this means that there is no cancer beyond the resection margin, which is referred to as a histopathological (or oncological) $\mathrm{R} 0$ resection. In several series, oncological $\mathrm{R} 0$ resection was accompanied by five-year survival rates of $18 \%$ to $35 \%$. An oncological RO resection is achieved by the surgical technique of extended tissue clearance (8).

\section{INDICATIONS AND LIMITS OF SURGERY}

While surgical resection of the tumour-bearing pancreas along with clearance of adjacent tissues offers the best chance for cure, only $10 \%$ to $25 \%$ of patients have resectable disease at the time of diagnosis (Table 2). Even in so-called oncological RO resections, cure is not always possible. Therefore, surgical therapy of pancreatic cancer is limited. Multimodal therapy, either surgery combined with adjuvant
TABLE 1

Favourable prognostic factors for pancreatic cancer

\begin{tabular}{ll}
\hline Factor & Author, year (reference) \\
\hline $\begin{array}{l}\text { Tumour size less than 2 to 3 cm } \\
\begin{array}{l}\text { Negative for lymph node } \\
\text { involvement }\end{array}\end{array}$ & $\begin{array}{l}\text { Tsuchiya et al, 1985 (7) } \\
\text { Cameron et al, 1991 (1) }\end{array}$ \\
$\begin{array}{l}\text { Negative for nerve infiltration } \\
\begin{array}{l}\text { Negative for vascular wall } \\
\text { infiltration }\end{array}\end{array}$ & $\begin{array}{l}\text { Nagakawa et al, 1991 (6) } \\
\text { Ishikawa et al, 1988 (14) }\end{array}$ \\
$\begin{array}{l}\text { Well-differentiated cells } \\
\text { Diploid DNA }\end{array}$ & Geer and Brennan, 1993 (2) \\
$\begin{array}{l}\text { Cancer genes: Wild-type } \\
\text { of } p 53, \text { p16, DPC4 }\end{array}$ & Yeo et al, 1995 (15) \\
\hline
\end{tabular}

TABLE 2

The UIm experience with pancreatic cancer*

\begin{tabular}{lc}
\hline UICC Stage & Prevalence (\%) \\
\hline I & 2.5 \\
II & 6.2 \\
III & 14.6 \\
IV & 52.9 \\
X & 23.8 \\
\hline
\end{tabular}

*1000 patients from May 1982 to March 2001, Department of General Surgery, University of UIm, Germany. UICC International Union Against Cancer

therapy or palliative multimodal treatment, is required in almost every case (Table 3 ).

Resection is more frequently undertaken in centres that see large numbers of patients with pancreatic cancer (3). Nevertheless, the long term survival is determined by the biology of the disease. Five-year survival rates range from $3 \%$ to $24 \%$, but rarely exceed $10 \%$ in large collective series. The median survival time is usually between 12.8 and 15.8 months after surgery (Table 4).

The decision to operate is based on the results of thinsliced helical computed tomography and laparoscopy, combined with laparoscopic ultrasound examination of the liver and vessel walls. Patients with stage I and II disease according to the criteria of the International Union Against Cancer (UICC) should undergo surgery with the intent to cure. Patients with UICC stage III ductal pancreatic cancer have lymph node metastases without local or distant metastases or vascular invasion. In these patients, the tumour is frequently resectable, but the chances for long term survival are low. Resection does not improve survival in patients with distant peritoneal metastases, lung metastases, malignant ascites, or infiltration of the mesentery of the small or large bowel. Cure is rarely achieved if there is circumferential infiltration of a blood vessel, such as the superior mesenteric or hepatic arteries (Tables 2, 4). 
TABLE 3 The Ulm experience with pancreatic cancer
management $^{\star}$

\begin{tabular}{lc}
\hline Management & Frequency (\%) \\
\hline Surgical treatment & 82.6 \\
Pancreatic resection & 42.7 \\
Resection of the head of & 31.5 \\
the pancreas & \\
Resection of the left side of & 9.0 \\
the pancreas & \\
Total pancreatectomy & 2.2 \\
Bypass surgery & 20.7 \\
Gastric & 3.1 \\
Biliary tract & 9.1 \\
Both & 8.5 \\
Other operations & 19.2 \\
Nonoperative treatment & 52.5 \\
Adjuvant therapy & 14.1 \\
Regional chemotherapy & 6.6 \\
Systemic therapy & 7.5 \\
Palliative therapy & 38.4 \\
Regional chemotherapy & 14.8 \\
Systemic therapy & 23.6
\end{tabular}

*1000 patients from May 1982 to March 2001, Department of General Surgery, University of UIm, Germany

\section{LOCAL OR EXTENDED LYMPH NODE DISSECTION?}

No definite conclusions can be drawn about the effectiveness of extended lymph node dissection from the available evidence. Even though many centres have adopted the practice of radical lymph node resection, there is still residual disease (Table 1). Compared with standard resection, this technique has extended survival, even in patients with advanced cancer (UICC stage III), but median survival rates still do not exceed 12 to 20 months (Table 4).

Japanese surgeons were the first to demonstrate an increase in median (but not long term) survival after extensive lymph node dissection. The radical procedure is not confined to removal of lymph nodes around the head of the pancreas, but includes the removal of retroperitoneal connective tissue and the nerve plexus on the right side of the aorta. Several groups have reported favourable results with this method $(8,9)$. Numerous Japanese studies have shown an impressively high five-year survival rate of between $25 \%$ and $35 \%$. As expected, the best results are achieved when the patient has a small tumour and no demonstrable lymph node metastases.

The gold standard in the evaluation of any clinical treatment modality is the prospective randomized, controlled trial. Only one such trial of radical lymph node dissection has been performed to date (8). In this multicentre trial that included five Italian and one American institution, 81 patients with ductal adenocarcinoma of the pancreatic head were enrolled. This study demonstrated no significant difference in survival between the group that underwent
TABLE 4

Surgical options for pancreatic adenocarcinoma

\begin{tabular}{ll}
\hline Approach & Achievable result \\
\hline Increase in resection rate & $>25 \%$ \\
Increase in achieving an R0 resection & $>50 \%$ \\
Decrease in hospital mortality & $<5 \%$ \\
after resection & \\
Increase in survival after oncological & 2 year $>40 \%$ \\
R0 resection & 5 year $>25 \%$ \\
Extended operative tissue clearance & Prolonged individual \\
of N1 and N2 lymph nodes, and & survival \\
perivascular and retroperitoneal tissue & \\
Portal and superior mesenteric vein & Prolonged individual \\
resection in V1- and V2-positive & survival \\
patients, without circumferential & \\
involvement of the vein & \\
Selective use of PPPD & Reduced early and late \\
& morbidity
\end{tabular}

N1 Metastasis to group 1 lymph nodes according to the classification of the Japan Pancreas Society (17); N2 Metastasis to group 2 lymph nodes (17); PPPD Pylorus-preserving pancreatoduodenectomy; V1 Suspected venous invasion (17); V2 Definite venous invasion (17)

extended lymph node dissection and the group that underwent local resection. A posteriori subgroup analysis revealed a significantly longer survival time among patients with lymph node metastasis who underwent the radical procedure than among those who underwent traditional local resection. The perioperative morbidity and mortality did not differ between the two groups. Debilitating diarrhea can occur, however, after circumferential dissection around the superior mesenteric artery. Extended perivascular tissue clearance, including the extrapancreatic nerve ganglia on the right side of the aorta and complete perivascular skeletonization of the superior mesenteric artery, results in severe impairment of the quality of life.

\section{ADJUVANT CHEMOTHERAPY}

Even UICC stage I cancers are usually not limited to the pancreas when methods of molecular biology are employed to examine cancer cell dissemination. Such techniques have demonstrated infiltration with cancer cells in $50 \%$ of lymph nodes that are histologically negative for cancer. After ostensibly curative resection, cancer recurs locally in $70 \%$ to $90 \%$ of cases, usually in the liver or the peritoneal cavity, which has led to an increased interest in adjuvant or multimodal therapy. Because resection alone results in insufficient disease control, adjuvant chemotherapy, and combined radiation and chemotherapy have been attempted (10).

The first important study in adjuvant therapy randomly assigned 22 patients to surgery alone and 21 patients to adjuvant therapy, and was completed by a gastrointestinal study group in the United States (11). Surgery with postoperative radiochemotherapy resulted in a significantly longer median survival time compared with surgery alone (20 ver- 
sus 11 months). The trial of the European Organization for the Research and Treatment of Cancer - Gastrointestinal Tract Cancer Cooperative Group (EORTC-GITCCS) involved 110 patients in each treatment arm (12). Patients who underwent surgery alone had a median survival time of 19.1 months, compared with 23.5 months for those who had surgery and adjuvant therapy. The benefit from adjuvant radiochemotherapy seemed to be greater for patients with pancreatic cancer than for those with periampullary cancer.

Neoadjuvant radiochemotherapy was evaluated in a recently published prospective study by Snady et al (13). They used fractionated radiotherapy and chemotherapy protocols including 5-fluorouracil, streptozocin and cisplatin. The median survival time for patients given neoadjuvant therapy was 23.6 months, compared with 14 months for the group that underwent surgery alone. The survival time of the 46 downstaged patients (on the basis of complete response and partial response) was 25.5 months. The patients who finally had a surgical resection after neoadjuvant radiochemotherapy had a three-year survival rate of $32 \%$. Although this was not a randomized trial, the median

\section{REFERENCES}

1. Cameron JL, Crist DW, Sitzmann JV, et al. Factors influencing survival after pancreaticoduodenectomy for pancreatic cancer. Am J Surg 1991;161:120-5.

2. Geer RJ, Brennan MF. Prognostic indicators for survival after resection of adenocarcinoma of the pancreas. Am J Surg 1993;165:68-73.

3. Beger HG, Gansauge F, Birk D. Lymph node dissection. In: Cameron J, ed. Atlas of Clinical Oncology: Pancreatic Cancer. Hamilton: BC Decker, 2001:123-32.

4. Bittner R, Roscher R, Safi F, Dopfer HP, Scholzel E, Beger HG. Prognostic influence of tumor size and lymph node involvement in pancreatic carcinoma. Chirurgie 1989;60:240-5.

5. Heeckt P, Safi F, Binder T, Büchler M. Free intraperitoneal tumor cells in pancreatic cancer - significance for clinical course and therapy. Chirurgie 1992;63:563-7.

6. Nagakawa T, Konishi I, Ueno K, et al. The results and problems of extensive radical surgery for carcinoma of the head of the pancreas. Jpn J Surg 1991;21:262-7.

7. Tsuchiya R, Oribe T, Noda T. Size of the tumor and other factors influencing prognosis of carcinoma of the head of the pancreas. Am J Gastroenterol 1985;80:459-62.

8. Pedrazoli P, DiCarlo V, Dionigi R, et al. Standard versus extended lymphadenectomy associated with pancreatoduodenectomy in the surgical treatment of adenocarcinoma of the head of the pancreas. Lymphadenectomy Study Group. Ann Surg 1998;228:508-17.

9. Yeo CJ, Cameron JL, Sohn TA, et al. Pancreaticoduodenectomy with or without extended retroperitoneal lymphadenectomy for survival time of 23.6 months after neoadjuvant therapy is encouraging (13).

\section{CONCLUSIONS}

Surgical resection affords a significant survival benefit for patients with UICC stage I and II pancreatic cancer. The main goal of surgery is to achieve an oncological RO resection. This $\mathrm{R} 0$ resection must include distant tissues, such as the perivascular nerves, extrapancreatic ganglia, lymph tissue in the hepatoduodenal ligament and lymph nodes in the paramesenteric location. We recommend adjuvant chemotherapy for all patients after surgical resection. Uncontrolled prospective trials have shown a five-year survival in one-third of patients following $\mathrm{RO}$ resection combined with adjuvant chemotherapy. A small group of patients with UICC stage III cancer may benefit from neoadjuvant radiochemotherapy. In advanced pancreatic cancer, palliative chemotherapy (consisting of 5-fluorouracil plus folinic acid) is still the treatment of choice. Newer drugs, such as gemcitabine, seem to offer slightly better short term survival.

periampullary adenocarcinoma: comparison of morbidity and mortality and short-term outcome. Ann Surg 1999;229:613-24.

10. Birk D, Beger HG. Curr Gastroenterol Rep. (In press)

11. Gastrointestinal Tumor Study Group. Further evidence of effective adjuvant combined radiation and chemotherapy following curative resection of pancreatic cancer. Cancer 1987;59:2006-10.

12. Klinkenbijl JH, Jeekel J, Sahmoud T, et al. Adjuvant radio-therapy and 5-fluorouracil after curative resection of cancer of the pancreas and periampullary region: phase III trial of the EORTC gastrointestinal tract cancer cooperative group. Ann Surg 1999;230:776-84.

13. Snady H, Bruckner H, Cooperman A, Paradiso J, Kiefer L. Survival advantage of combined chemoradiotherapy compared with resection as the initial treatment of patients with regional pancreatic carcinoma. An outcomes trial. Cancer 2000;89:314-27.

14. Ishikawa O, Ohhigashi $\mathrm{H}$, Sasaki $\mathrm{Y}$, et al. Practical usefulness of lymphatic and connective tissue clearance for the carcinoma of the pancreas head. Ann Surg 1988;208:215-20.

15. Yeo CJ, Cameron JL, Lillemoe KD, et al. Pancreaticoduodenectomy for cancer of the head of the pancreas. 201 patients. Ann Surg 1995;221:721-31; discussion 731-3.

16. Rozenblum E, Schutte M, Goggins M, et al. Tumor-suppressive pathways in pancreatic carcinoma. Cancer Res 1997;57:1731-4.

17. Japan Pancreas Society. Classification of Pancreatic Carcinoma, First English Edition. Tokyo: Kanehara \& Co, 1996:6,8-13. 


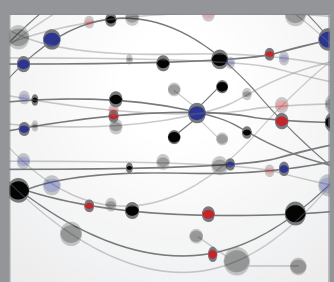

The Scientific World Journal
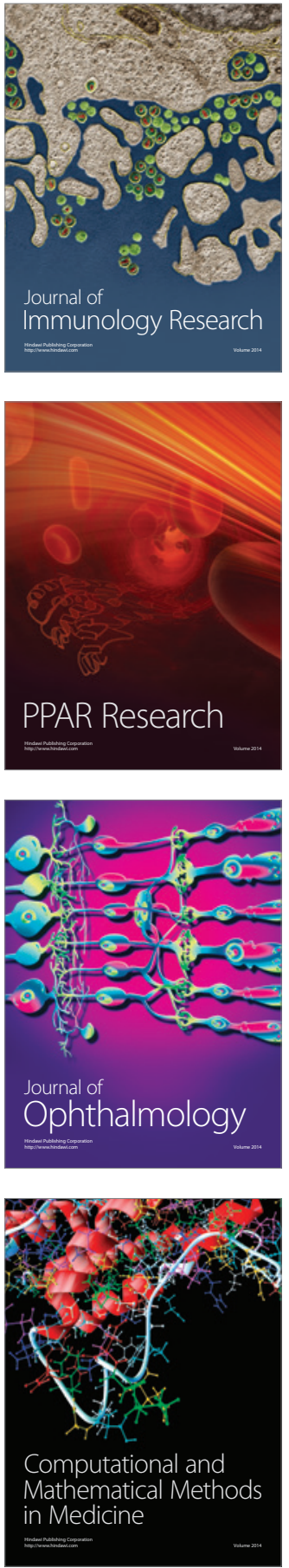

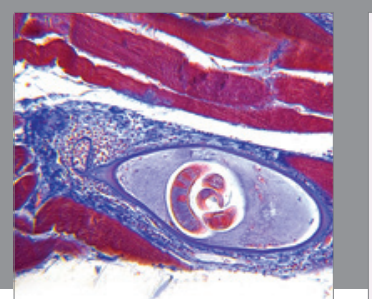

Gastroenterology Research and Practice

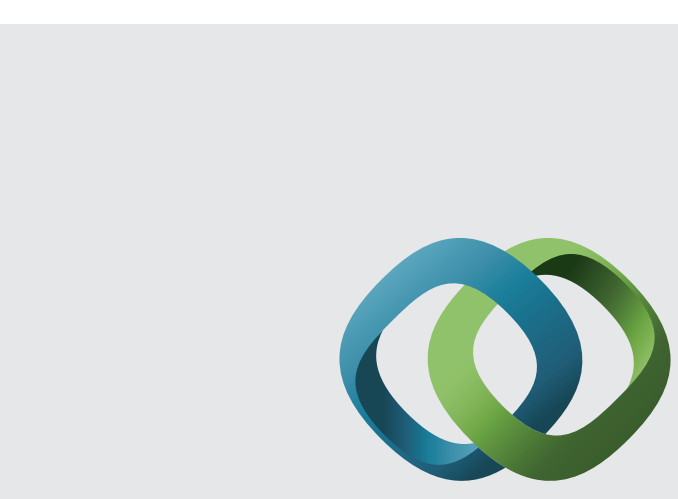

\section{Hindawi}

Submit your manuscripts at

http://www.hindawi.com
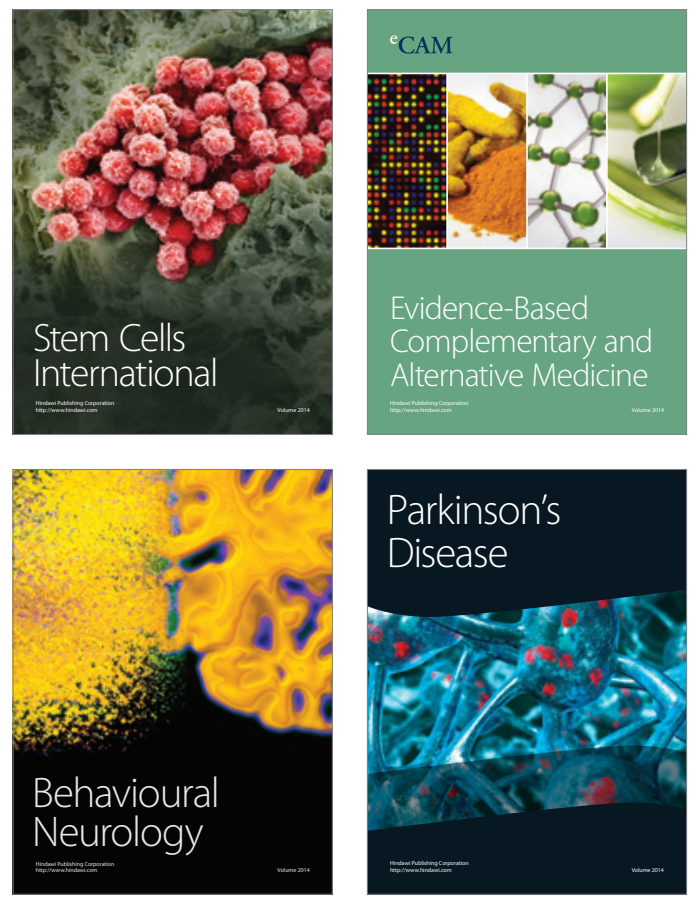
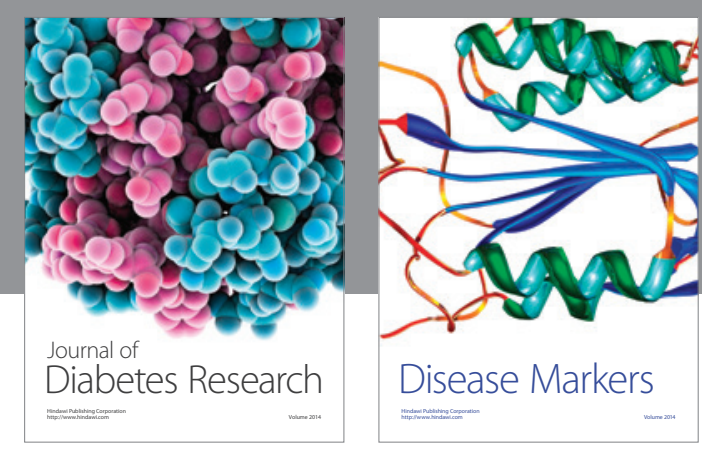

Disease Markers
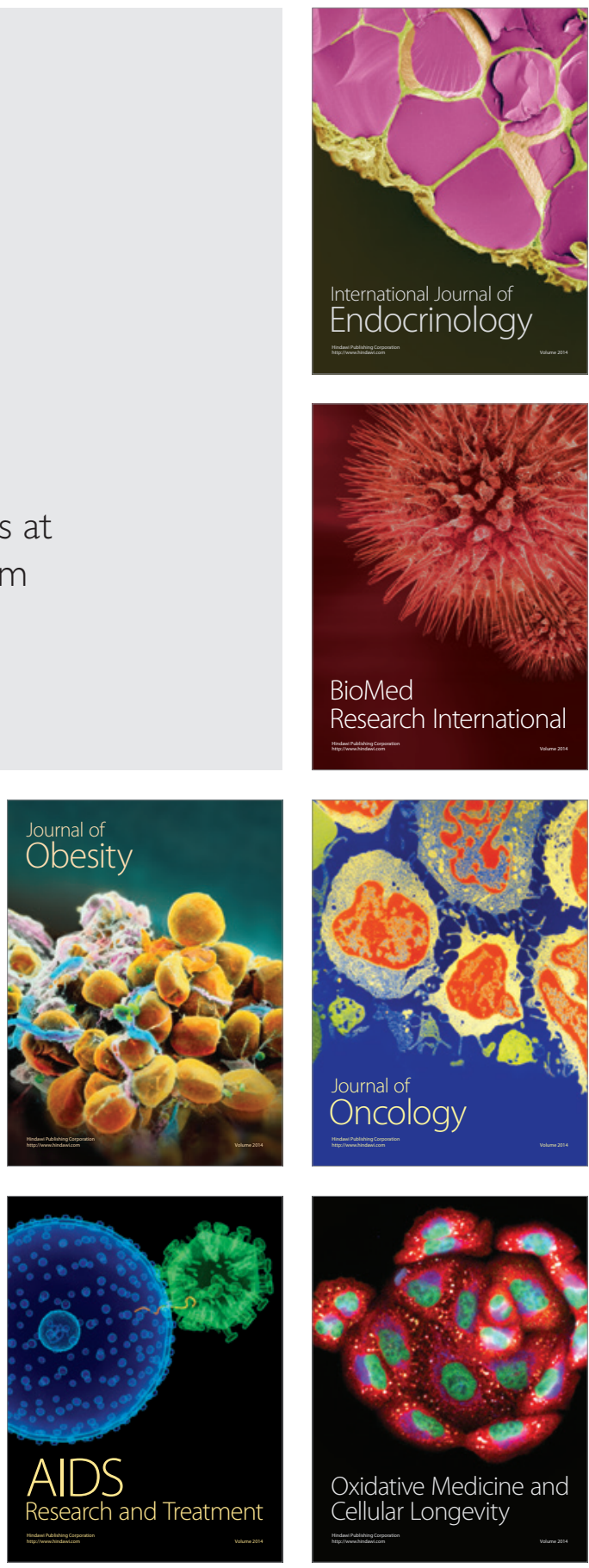